\title{
Saxagliptin Efficacy and Safety in Patients With Type 2 Diabetes and Moderate Renal Impairment
}

\author{
Shira Perl $\cdot$ William Cook $\cdot$ Cheryl Wei $\cdot$ Nayyar Iqbal $\cdot$ \\ Boaz Hirshberg
}

Received: April 4, 2016/Published online: July 11, 2016

(C) The Author(s) 2016. This article is published with open access at Springerlink.com

\begin{abstract}
Introduction: Type 2 diabetes (T2D) is the leading cause of chronic kidney disease (CKD). The recommended dose of the dipeptidyl peptidase- 4 inhibitor saxagliptin is $2.5 \mathrm{mg}$ in patients with moderate or severe renal impairment (creatinine clearance $\leq 50 \mathrm{~mL} / \mathrm{min}$ ). In this post hoc analysis, we assessed the effect of saxagliptin 2.5 and $5 \mathrm{mg}$ /day versus placebo on glycemic measures in patients with $\mathrm{T} 2 \mathrm{D}$ and estimated glomerular filtration rate $45-60 \mathrm{~mL} / \mathrm{min} / 1.73 \mathrm{~m}^{2}$.
\end{abstract}

Methods: Efficacy and safety data were pooled from nine 24-week, randomized, placebo-controlled clinical trials.

Results: The majority (56-61\%) of patients were women aged $<65$ years with glycated hemoglobin (A1C) 8.1-8.2\%; half of the patients had a T2D duration $\geq 5$ years. Mean

Enhanced content To view enhanced content for this article go to http://www.medengine.com/Redeem/ 11E4F06075D11E10.

S. Perl $(\bowtie) \cdot$ C. Wei $\cdot$ N. Iqbal

AstraZeneca, One Medimmune Way, Gaithersburg,

MD, USA

e-mail: shira.perl@astrazeneca.com

W. Cook · B. Hirshberg

MedImmune, LLC, Gaithersburg, MD, USA change from baseline in A1C was significantly greater with saxagliptin $2.5(-0.6 \%, P=0.036$ vs placebo) and $5 \mathrm{mg} /$ day $(-0.9 \%, P<0.001$ vs placebo) compared with placebo $(-0.2 \%)$. There were numerically greater reductions in fasting plasma glucose and 2-h postprandial glucose, and a significantly greater proportion of patients achieved A1C $<7 \%$ with saxagliptin $5 \mathrm{mg} /$ day $(44.8 \%)$ compared with placebo (20.0\%, $P=0.004$ vs placebo). The incidence of hypoglycemia was not significantly different across groups $(16.2 \%$ in the saxagliptin $5-\mathrm{mg} / \mathrm{day}, \quad 12.2 \%$ in the saxagliptin $2.5-\mathrm{mg} /$ day, and $11.3 \%$ in the placebo groups).

Conclusion: These results suggest that saxagliptin 2.5 and $5 \mathrm{mg}$ /day improve glycemic control and are generally well tolerated in patients with T2D and moderate CKD.

Trial registration: ClinicalTrials.gov identifier, NCT00121641, NCT00316082, NCT00698932, NCT00918879, NCT00121667, NCT00661362, NCT00313313, NCT00295633, NCT00757588.

Funding: AstraZeneca, Gaithersburg, MD, USA.

Keywords: Chronic kidney disease; Dipeptidyl peptidase-4 inhibitor; Estimated glomerular filtration rate; Saxagliptin; Type 2 diabetes 


\section{INTRODUCTION}

Worldwide, diabetes is the leading cause of chronic kidney disease (CKD) [1], which is defined by an estimated glomerular filtration rate (eGFR) of $<60 \mathrm{~mL} / \mathrm{min} / 1.73 \mathrm{~m}^{2}$ or an albumin/creatinine ratio $\geq 30 \mathrm{mg} / \mathrm{g}$ for more than 3 months [2]. In the United States, the prevalence of CKD among individuals with diabetes is estimated to be $\sim 40 \%$ based on eGFR and/or albuminuria [3]. A recent analysis of the National Health and Nutrition Examination Survey (1999-2012) database reported that $12.9 \%$ of patients with type 2 diabetes (T2D) had eGFR in the upper range of moderate CKD (stage 3a: 45 to $<60 \mathrm{~mL} / \mathrm{min}$ / $1.73 \mathrm{~m}^{2}$ ) [4].

Treatment of patients with T2D and CKD is challenging because many antidiabetes medications are cleared by the kidneys and require dosage adjustment to avoid hypoglycemia [5]. Saxagliptin is a dipeptidyl peptidase- 4 inhibitor that improves glycemic control in patients with T2D as monotherapy or in combination with other antidiabetes medications and imparts a very low risk of hypoglycemia [6-14]. Saxagliptin is metabolized to an active metabolite by the liver and, along with the parent molecule, is eliminated mainly by the kidney [15]. Therefore, the recommended dose of saxagliptin is $2.5 \mathrm{mg} /$ day in patients with moderate or severe renal impairment (creatinine clearance $[\mathrm{CrCl}] \leq 50 \mathrm{~mL} / \mathrm{min}$ ), which is half the recommended dose ( $5 \mathrm{mg} /$ day) for patients with normal kidney function [16]. The objective of this post hoc analysis was to assess the efficacy and safety of saxagliptin 2.5 and $5 \mathrm{mg} /$ day versus placebo using data pooled from saxagliptin clinical trials in patients with T2D and moderate renal impairment (eGFR 45-60 mL/min/1.73 $\mathrm{m}^{2}$ ).

\section{METHODS}

Efficacy and safety data were pooled from nine 24-week, randomized, placebo-controlled clinical trials, which included 4 trials of saxagliptin monotherapy (NCT00121641 [6], NCT00316082 [7], NCT00698932 [8], and NCT00918879 [9]), 2 trials of saxagliptin add-on to metformin (NCT00121667 [10] and NCT00661362 [11]), and 1 trial each of saxagliptin add-on to glyburide (NCT00313313 [12]), add-on to a thiazolidinedione (NCT00295633 [13]), and add-on to insulin with or without metformin (NCT00757588 [14]). Study designs and inclusion and exclusion criteria have been previously reported in detail [6-14]. Only patients with eGFR of $45-60 \mathrm{~mL} / \mathrm{min} / 1.73 \mathrm{~m}^{2}$ at baseline were included in this analysis. eGFR was calculated from serum creatinine using the Modification of Diet in Renal Disease equation [17]. Safety was assessed by adverse events (AEs), serious AEs (SAEs), and laboratory values.

Differences in changes from baseline in glycated hemoglobin (A1C), fasting plasma glucose (FPG), and 2-h postprandial glucose (PPG) following an oral glucose tolerance test were assessed using an analysis of covariance model with treatment as the factor, baseline value as the covariate, and study as the random effect for the saxagliptin versus the placebo groups. The proportion of patients achieving A1C $<7 \%$ at the end of the 24 -week treatment period was analyzed using the Cochran-Mantel-Haenszel general association test stratified by study. The incidence of hypoglycemia with saxagliptin compared with placebo was assessed by Fisher exact test. Statistical analyses were performed with Statistical Analysis System (SAS) software (SAS Institute, Cary, NC, USA). 


\section{Compliance with Ethics Guidelines}

All procedures were in accordance with the ethical standards of the responsible committee on human experimentation (institutional and national) and with the Helsinki Declaration of 1964, as revised in 2013. Informed consent was obtained from all patients for inclusion in the study. This article is based on previously conducted studies and does not involve any new studies of human or animal subjects performed by any of the authors.

\section{RESULTS}

A total of 188 patients with eGFR $45-60 \mathrm{~mL} / \mathrm{min} / 1.73 \mathrm{~m}^{2}$ at baseline were identified. The majority of patients were white women $<65$ years old with a mean baseline A1C of $8.1-8.2 \%$ and a mean T2D duration of
6.5-8.6 years (Table 1 ). Mean eGFR at baseline was $54-55 \mathrm{~mL} / \mathrm{min} / 1.73 \mathrm{~m}^{2}$. Demographics and baseline characteristics were similar across treatment groups.

At 24 weeks, the mean change from baseline in A1C was significantly greater with saxagliptin $2.5 \mathrm{mg} /$ day (mean [95\% CI] difference from placebo $-0.6 \%[-0.8 \%,-0.0 \%] ; P=0.036)$ and $5 \mathrm{mg} /$ day $\quad(-0.9 \% \quad[-1.0 \%,-0.4 \%] ; \quad P<0.001)$ compared with placebo (Fig. 1a). There were numerically greater, but not statistically significant, reductions from baseline in FPG (Fig. 1b; mean [95\% CI] difference from placebo $2.5 \mathrm{mg} / \mathrm{day},-10$ [-21.7, 10.2] mg/dL; $5 \mathrm{mg} /$ day, -16 [-27.7, 1.9] mg/dL) and 2-h PPG (Fig. 1c; mean $[95 \% \mathrm{CI}]$ difference from placebo $2.5 \mathrm{mg} / \mathrm{day}, \quad-48.6 \quad[-51.4,8.4] \quad \mathrm{mg} / \mathrm{dL}$; $5 \mathrm{mg} /$ day, $-57.7 \quad[-47.0,8.8] \mathrm{mg} / \mathrm{dL})$ with saxagliptin 2.5 and $5 \mathrm{mg} /$ day compared with placebo. A greater proportion of patients

Table 1 Demographics and baseline characteristics of patients with eGFR $45-60 \mathrm{~mL} / \mathrm{min} / 1.73 \mathrm{~m}^{2}$

\begin{tabular}{lclc}
\hline Characteristic & Placebo $(\boldsymbol{n}=\mathbf{7 1})$ & $\begin{array}{l}\text { Saxagliptin } \\
\mathbf{2 . 5} \mathbf{~ m g} / \mathbf{d a y} \\
(\boldsymbol{n}=\mathbf{4 9})\end{array}$ & $\begin{array}{l}\text { Saxagliptin } \\
\mathbf{5 ~ m g / d a y ~} \\
(\boldsymbol{n}=\mathbf{6 8})\end{array}$ \\
\hline Age, years & $62.9(7.1)$ & $63.4(7.9)$ & $61.8(9.3)$ \\
Women, $n$ (\%) & $40(56)$ & $30(61)$ & $41(60)$ \\
Race, $n(\%)$ & & $43(88)$ & $47(69)$ \\
White & $46(65)$ & $2(4)$ & $1(2)$ \\
Black & $1(1)$ & $4(8)$ & $19(28)$ \\
Asian & $23(32)$ & 0 & $1(2)$ \\
Other & $1(1)$ & $30.5(4.7)$ & $30.1(5.5)$ \\
BMI, $\mathrm{kg} / \mathrm{m}^{2}$ & $29.8(4.8)$ & $6.5(7.0)$ & $7.1(7.5)$ \\
Duration of T2D, years & $8.6(8.4)$ & $8.1(0.81)$ & $8.1(0.91)$ \\
AlC, $\%$ & $8.2(0.95)$ & $54.2(4.6)$ & $55.3(3.6)$ \\
eGFR, $\mathrm{mL} / \mathrm{min} / 1.73 \mathrm{~m}^{2}$ & $55.2(3.9)$ & &
\end{tabular}

Data are mean $(\mathrm{SD})$ unless otherwise noted

$A 1 C$ glycated hemoglobin, $B M I$ body mass index, eGFR estimated glomerular filtration rate, $S D$ standard deviation, $T 2 D$ type 2 diabetes 
a

$\begin{array}{rrrr}\text { Baseline, \% } & 8.2 & 8.1 & 8.1 \\ \mathrm{n} & 71 & 49 & 68\end{array}$

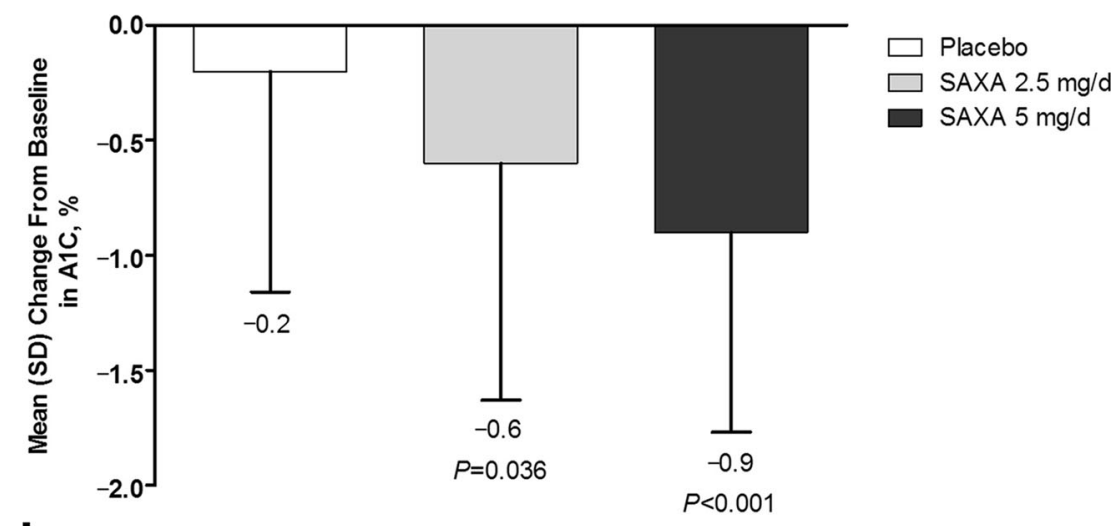

b

$\begin{array}{cr}\text { Baseline, } \mathrm{mg} / \mathrm{dL} & 170 \\ \mathrm{n} & 71\end{array}$
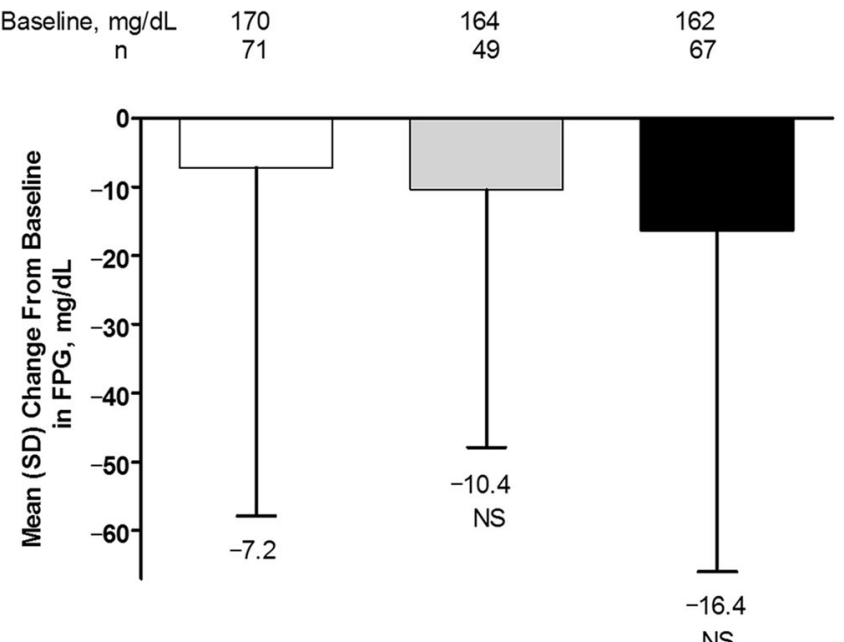

C

$\begin{array}{cccc}\text { Baseline, } \mathrm{mg} / \mathrm{dL} & 284 & 304 & 305 \\ \mathrm{n} & 52 & 45 & 57\end{array}$

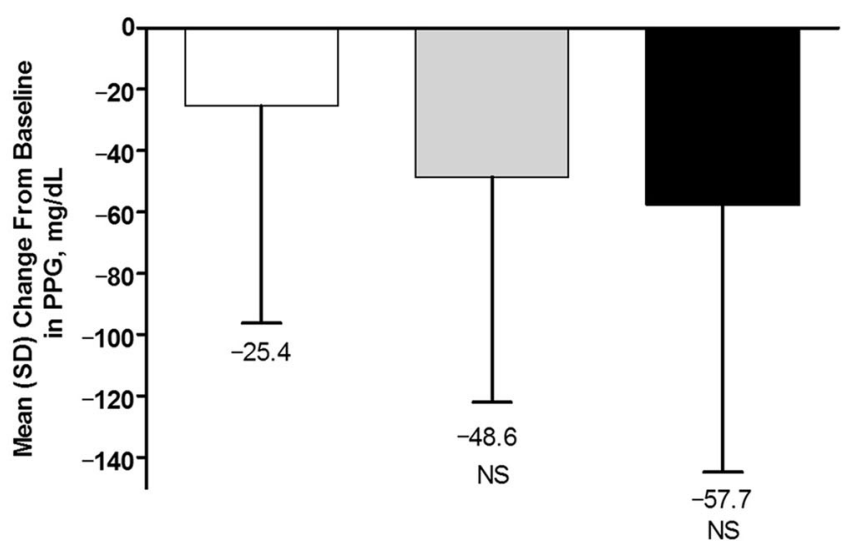

Fig. 1 Mean change from baseline to week 24 in a A1C, b FPG, and c 2-h PPG. $A 1 C$ glycated hemoglobin, FPG fasting plasma glucose, $N S$ nonsignificant, $P P G$ 2-h postprandial glucose, $S A X A$ saxagliptin, $S D$ standard deviation 


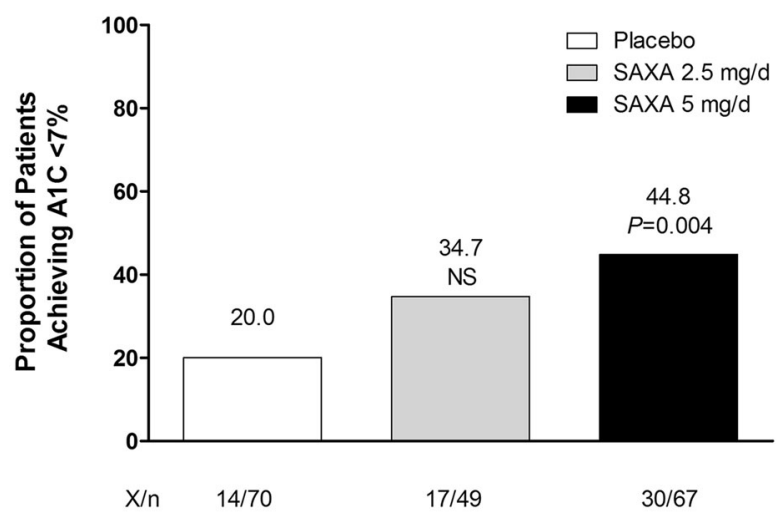

Fig. 2 Proportion of patients achieving A1C $<7 \%$ at week 24. $A 1 C$ glycated hemoglobin, NS nonsignificant, $S A X A$ saxagliptin

achieved $\mathrm{A} 1 \mathrm{C}<7 \%$ at week 24 with saxagliptin $2.5 \mathrm{mg} /$ day (34.7\%, NS) and $5 \mathrm{mg} /$ day (44.8\%, $P=0.004$ vs placebo) compared with placebo (20.0\%; Fig. 2).

Overall, AEs were reported more frequently with saxagliptin treatment compared with placebo (Table 2). AEs and SAEs related to kidney function were infrequent. The proportion of patients with increased blood creatinine was generally similar with placebo (5.6\%) and saxagliptin treatment (4.4-8.2\%). There was $1 \mathrm{SAE}$ of acute renal failure in the saxagliptin $2.5-\mathrm{mg} /$ day group and none in the saxagliptin 5-mg/day and placebo groups. The 61-year-old woman was overweight and had a history of hypertension, hypercholesterolemia, hypertriglyceridemia, and probable baseline CKD exacerbated by relative volume depletion and concomitant medications. Saxagliptin was discontinued, and the event resolved following treatment. The acute renal failure was considered unlikely to be related to saxagliptin. In general, AEs were similar with saxagliptin 2.5 and $5 \mathrm{mg} /$ day, although AEs related to pain were more frequent with saxagliptin 5 than $2.5 \mathrm{mg} /$ day. The proportion of patients with hypoglycemia was numerically greater, but not significantly different, compared with placebo (11.3\%) in the saxagliptin $2.5-\mathrm{mg} /$ day $(12.2 \%, P=1.000)$ and $5-\mathrm{mg} /$ day groups $(16.2 \%, \quad P=0.464)$. At 24 weeks, there were small mean increases in eGFR from baseline in all treatment groups (Fig. 3).

\section{DISCUSSION}

Impaired renal function is common in patients with T2D, especially in those $\geq 65$ years [4], and is independently associated with increased mortality, cardiovascular events, and hospitalization [18, 19]. Pharmacotherapy in patients with T2D can be challenging and therapeutic options may be limited because a reduced GFR results in the accumulation of certain drugs and/or their metabolites that may increase the risk of side effects or hypoglycemia $[5,20]$. In this analysis of patients with T2D and moderate CKD, saxagliptin 2.5 and $5 \mathrm{mg}$ /day significantly reduced $\mathrm{A} 1 \mathrm{C}$ and resulted in numerically larger reductions in FPG and PPG compared with placebo. In addition, saxagliptin $5 \mathrm{mg} /$ day doubled the proportion of patients achieving A1C $<7 \%$ after 24 weeks of treatment compared with placebo. These improvements in glycemic control with saxagliptin 2.5 and $5 \mathrm{mg} /$ day were accompanied by small increases in overall AEs and SAEs compared with placebo, but AEs related to renal function were infrequent and episodes of hypoglycemia were generally similar across treatment groups. Of note, eGFR remained stable over the 24 weeks of treatment with saxagliptin as well as with placebo.

Our results using data pooled from 9 randomized clinical trials of saxagliptin 2.5 and $5 \mathrm{mg} /$ day are in agreement with the results of a previously reported 12-week 
Table 2 Adverse events

\begin{tabular}{|c|c|c|c|}
\hline \multirow[t]{2}{*}{ Adverse event } & \multicolumn{3}{|c|}{ Patients, $n(\%)$} \\
\hline & $\begin{array}{l}\text { Placebo } \\
n=71\end{array}$ & $\begin{array}{l}\text { Saxagliptin } \\
2.5 \mathrm{mg} / \mathrm{day} \\
n=49\end{array}$ & $\begin{array}{l}\text { Saxagliptin } \\
5 \mathrm{mg} / \text { day } \\
n=68\end{array}$ \\
\hline$\geq 1 \mathrm{AE}$ & $46(64.8)$ & $41(83.7)$ & $51(75.0)$ \\
\hline$\geq 1 \mathrm{SAE}$ & $5(7.0)$ & $6(12.2)$ & $6(8.8)$ \\
\hline \multicolumn{4}{|l|}{ Most common AEs ( $\geq 5 \%)$} \\
\hline Urinary tract infection & $6(8.5)$ & $6(12.2)$ & $6(8.8)$ \\
\hline Influenza & $5(7.0)$ & $5(10.2)$ & $7(10.3)$ \\
\hline Nasopharyngitis & $3(4.2)$ & $4(8.2)$ & $4(5.9)$ \\
\hline Pharyngitis & $4(5.6)$ & $4(8.2)$ & $2(2.9)$ \\
\hline Upper respiratory infection & $4(5.6)$ & $4(8.2)$ & $4(5.9)$ \\
\hline Bronchitis & $4(5.6)$ & $3(6.1)$ & $2(2.9)$ \\
\hline Arthralgia & $4(5.6)$ & $6(12.2)$ & $2(2.9)$ \\
\hline Back pain & $3(4.2)$ & $2(4.1)$ & $5(7.4)$ \\
\hline Pain in extremity & $3(4.2)$ & $1(2.0)$ & $5(7.4)$ \\
\hline Musculoskeletal pain & $1(1.4)$ & 0 & $4(5.9)$ \\
\hline Diarrhea & 0 & $3(6.1)$ & $3(4.4)$ \\
\hline Dyspepsia & $3(4.2)$ & $3(6.1)$ & $2(2.9)$ \\
\hline Headache & $2(2.8)$ & $2(4.1)$ & $4(5.9)$ \\
\hline Increased blood creatinine & $4(5.6)$ & $4(8.2)$ & $3(4.4)$ \\
\hline Pruritus & 0 & $3(6.1)$ & 0 \\
\hline Peripheral edema & $4(5.6)$ & $2(4.1)$ & $4(5.9)$ \\
\hline Hypertension & $6(8.5)$ & $4(8.2)$ & $3(4.4)$ \\
\hline Hypotension & 0 & $3(6.1)$ & $1(1.5)$ \\
\hline Dyslipidemia & $4(5.6)$ & $2(4.1)$ & $1(1.5)$ \\
\hline Hypoglycemia & $8(11.3)$ & $6(12.2)$ & $11(16.2)$ \\
\hline
\end{tabular}

$A E$ adverse event, $S A E$ serious adverse event

clinical trial [21] with an extension to 52 weeks [22] of saxagliptin $2.5 \mathrm{mg} /$ day (plus background antidiabetes medications) in patients with T2D and moderate ( $\mathrm{CrCl} 30$ to $<50 \mathrm{~mL} / \mathrm{min})$, severe $(\mathrm{CrCl}<30 \mathrm{~mL} / \mathrm{min}$ and not receiving hemodialysis), or end-stage (receiving hemodialysis) kidney disease. In that study, saxagliptin was well tolerated across all stages of $\mathrm{CKD}$ and reduced $\mathrm{A} 1 \mathrm{C}$, compared with placebo, in patients with moderate and severe CKD.

Limitations of this study include its post hoc nature, relatively small number of patients, and duration of 24 weeks. However, the results of 


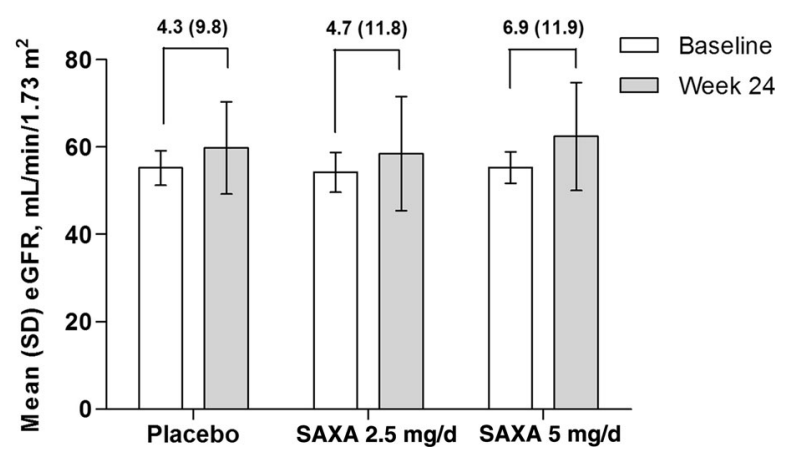

Fig. 3 Mean eGFR at baseline and 24 weeks. Mean (SD) change from baseline is shown above the bars. eGFR estimated glomerular filtration rate, $S A X A$ saxagliptin, $S D$ standard deviation

this analysis are consistent with a recently published subgroup analysis of the large saxagliptin cardiovascular outcomes trial Saxagliptin Assessment of Vascular Outcomes Recorded in Patients With Diabetes Mellitus (SAVOR) (ClinicalTrial.gov identifier, NCT01107886) [23]. In that analysis, patients were stratified according to baseline eGFR as having normal or mildly impaired renal function (eGFR $>50 \mathrm{~mL} / \mathrm{min} / 1.73 \mathrm{~m}^{2}$, $n=13,916$ ), moderate renal impairment (eGFR $\left.30-50 \mathrm{~mL} / \mathrm{min} / 1.73 \mathrm{~m}^{2}, \quad n=2240\right)$, or severe renal impairment (eGFR $<30 \mathrm{~mL} / \mathrm{min} / 1.73 \mathrm{~m}^{2}$, $n=336$ ). Compared with placebo, saxagliptin (5 or $2.5 \mathrm{mg} /$ day in patients with eGFR $\leq 50 \mathrm{~mL} / \mathrm{min} / 1.73 \mathrm{~m}^{2}$ ) significantly reduced A1C in all eGFR subgroups at 1 year, which persisted through a median follow-up of 2 years. Saxagliptin also significantly reduced progressive microalbuminuria in patients with normal or mildly reduced renal function $(P<0.0001)$ and in those with moderate-to-severe renal impairment $(P=0.04)$ based on improvement or less worsening of urinary albumin:creatinine ratio compared with placebo [23].

\section{CONCLUSION}

In conclusion, saxagliptin at doses of 2.5 or $5 \mathrm{mg} /$ day was equally well tolerated and improved glycemic control in patients with moderate renal impairment who have limited treatment options.

\section{ACKNOWLEDGMENTS}

Some of the data from this study were presented at the American Diabetes Association 75th Scientific Sessions, June 5-9, 2015, Boston, MA.

This study and article processing charges were funded by AstraZeneca, Gaithersburg, MD.

All named authors meet the International Committee of Medical Journal Editors (ICMJE) criteria for authorship for this manuscript, take responsibility for the integrity of the work as a whole, and have given final approval to the version to be published.

Medical writing support for the preparation of this manuscript was provided by Richard Edwards, PhD, and Janet Matsuura, PhD, from Complete Healthcare Communications, LLC (Chadds Ford, PA), with funding from AstraZeneca.

Disclosures. S. Perl, C. Wei and N. Iqbal are employees of AstraZeneca. W. Cook and B. Hirshberg are employees of MedImmune, LLC, a wholly owned subsidiary of AstraZeneca.

Compliance with Ethics Guidelines. All procedures were in accordance with the ethical standards of the responsible committee on human experimentation (institutional and national) and with the Helsinki Declaration of 
1964, as revised in 2013. Informed consent was obtained from all patients for inclusion in the study. This article is based on previously conducted studies and does not involve any new studies of human or animal subjects performed by any of the authors.

Open Access. This article is distributed under the terms of the Creative Commons Attribution-NonCommercial 4.0 International License (http://creativecommons.org/licenses/ by-nc/4.0/), which permits any noncommercial use, distribution, and reproduction in any medium, provided you give appropriate credit to the original author(s) and the source, provide a link to the Creative Commons license, and indicate if changes were made.

\section{REFERENCES}

1. Jha V, Garcia-Garcia G, Iseki K, et al. Chronic kidney disease: global dimension and perspectives. Lancet. 2013;382:260-72.

2. KDIGO 2012 clinical practice guideline for the evaluation and management of chronic kidney disease. Kidney Int. 2013;3(1):1-150.

3. Saran R, Li Y, Robinson B, et al. US renal data system 2014 annual data report: epidemiology of Kidney Disease in the United States. Am J Kidney Dis. 2015;65:A7.

4. Bailey RA, Wang Y, Zhu V, Rupnow MF. Chronic kidney disease in US adults with type 2 diabetes: an updated national estimate of prevalence based on Kidney Disease: improving Global Outcomes (KDIGO) staging. BMC Res Notes. 2014;7:415.

5. Arnouts P, Bolignano D, Nistor $\mathrm{I}$, et al. Glucose-lowering drugs in patients with chronic kidney disease: a narrative review on pharmacokinetic properties. Nephrol Dial Transplant. 2014;29:1284-300.

6. Rosenstock J, Aguilar-Salinas C, Klein E, et al. Effect of saxagliptin monotherapy in treatment-naive patients with type 2 diabetes. Curr Med Res Opin. 2009;25:2401-11.

7. Frederich R, McNeill R, Berglind N, Fleming D, Chen R. The efficacy and safety of the dipeptidyl peptidase-4 inhibitor saxagliptin in treatment-naive patients with type 2 diabetes mellitus: a randomized controlled trial. Diabetol Metab Syndr. 2012;4:36.

8. Pan CY, Yang W, Tou C, Gause-Nilsson I, Zhao J. Efficacy and safety of saxagliptin in drug-naive Asian patients with type 2 diabetes mellitus: a randomized controlled trial. Diabetes Metab Res Rev. 2012;28:268-75.

9. Kumar KMP, Jain SM, Tou C, Schützer K-M. Saxagliptin as initial therapy in treatment-naive Indian adults with type 2 diabetes mellitus inadequately controlled with diet and exercise alone: a randomized, double-blind, placebo-controlled, phase IIIb clinical study. Int J Diabetes Dev Ctries. 2014;34:201-9.

10. DeFronzo RA, Hissa MN, Garber AJ, et al. The efficacy and safety of saxagliptin when added to metformin therapy in patients with inadequately controlled type 2 diabetes with metformin alone. Diabetes Care. 2009;32:1649-55.

11. Yang W, Pan CY, Tou C, Zhao J, Gause-Nilsson I. Efficacy and safety of saxagliptin added to metformin in Asian people with type 2 diabetes mellitus: a randomized controlled trial. Diabetes Res Clin Pract. 2011;94:217-24.

12. Chacra AR, Tan GH, Apanovitch A, et al. Saxagliptin added to a submaximal dose of sulphonylurea improves glycaemic control compared with uptitration of sulphonylurea in patients with type 2 diabetes: a randomised controlled trial. Int J Clin Pract. 2009;63: 1395-406.

13. Hollander P, Li J, Allen E, Chen R, CV181-013 Investigators. Saxagliptin added to a thiazolidinedione improves glycemic control in patients with type 2 diabetes and inadequate control on thiazolidinedione alone. J Clin Endocrinol Metab. 2009;94:4810-9.

14. Barnett AH, Charbonnel B, Donovan M, Fleming D. Effect of saxagliptin as add-on therapy in patients with poorly controlled type 2 diabetes on insulin alone or insulin combined with metformin. Curr Med Res Opin. 2012;28:513-23.

15. Boulton DW, Li L, Frevert EU, et al. Influence of renal or hepatic impairment on the pharmacokinetics of saxagliptin. Clin Pharmacokinet. 2011;50:253-65.

16. Onglyza ${ }^{\circledR} \quad$ (saxagliptin). Full Prescribing Information. Wilmington, DE: AstraZeneca; 2015.

17. Levey AS, Bosch JP, Lewis JB, Greene T, Rogers N, Roth D. A more accurate method to estimate 
glomerular filtration rate from serum creatinine: a new prediction equation. Modification of Diet in Renal Disease Study Group. Ann Intern Med. 1999;130(6):461-70.

18. Afkarian M, Sachs MC, Kestenbaum B, et al. Kidney disease and increased mortality risk in type 2 diabetes. J Am Soc Nephrol. 2013;24:302-8.

19. Go AS, Chertow GM, Fan D, McCulloch CE, Hsu CY. Chronic kidney disease and the risks of death, cardiovascular events, and hospitalization. N Engl J Med. 2004;351:1296-305.

20. Abaterusso C, Lupo A, Ortalda V, et al. Treating elderly people with diabetes and stages 3 and 4 chronic kidney disease. Clin J Am Soc Nephrol. 2008;3:1185-94.
21. Nowicki M, Rychlik I, Haller H, Warren L, Suchower L, Gause-Nilsson I. Saxagliptin improves glycaemic control and is well tolerated in patients with type 2 diabetes mellitus and renal impairment. Diabetes Obes Metab. 2011;13:523-32.

22. Nowicki M, Rychlik I, Haller $H$, et al. Long-term treatment with the dipeptidyl peptidase-4 inhibitor saxagliptin in patients with type 2 diabetes mellitus and renal impairment: a randomised controlled 52-week efficacy and safety study. Int J Clin Pract. 2011;65:1230-9.

23. Udell JA, Bhatt DL, Braunwald E, et al. Saxagliptin and cardiovascular outcomes in patients with type 2 diabetes and moderate or severe renal impairment: observations from the SAVOR-TIMI 53 trial. Diabetes Care. 2015;38:696-705. 